\title{
GAMBARAN PENGETAHUAN REMAJA PUTRI TENTANG KESEHATAN REPRODUKSI KELAS X SMAN 1 LALAN MUSI BANYUASIN
}

\author{
Lilik Pranata \\ Progran Studi Ilmu Keperawatan UNIKA Musi Charitas \\ Email: lilikpranata390@yahoo.co.id
}

\begin{abstract}
Reproductive health is a state of complete physical, mental and social well-being not only free from disease or disability in all aspects related to the reproductive system, its functions and processes. Reproductive health includes: reproductive organs, adolescent sexual behavior, pregnancy, risky sexual behavior of adolescents, sexually transmitted diseases (STDs).Objective: Knowing the image of young women's knowledge about reproductive health class X SMAN 1 Lalan Musi Banyuasin.Method: Descriptive quantitative by using Cross Sectional design done with interview technique with questioner to 60 respondents with purposive sampling technique.Results: Knowledge of reproduction tools, 34 respondents (56.7\%) had enough knowledge and 11 respondents (18.3\%) had good knowledge. Knowledge of adolescent sexual behavior, 25 respondents $(41,6)$ have enough knowledge and 16 respondents $(26,7 \%)$ have good knowledge. Knowledge of pregnancy, 33 respondents (55\%) have enough knowledge and 5 respondents (8.3\%) have good knowledge. Knowledge about risky sexual behavior, 25 respondents (42\%) have less knowledge and 13 respondents $(21.6 \%)$ have good knowledge. Knowledge of sexually transmitted diseases (STDs), 35 respondents (58.3\%) had less knowledge and 7 respondents (11.7\%) had good knowledge. Improving adolescent knowledge should be carried out for health counseling to schools, as well as providing additional materials on reproductive health and using UKS facilities to the maximum extent possible.
\end{abstract}

Keywords: Knowledge; Youth, Reproductive Health

\begin{abstract}
ABSTRAK
Kesehatan reproduksi merupakan Suatu keadaan sejahtera fisik, mental dan sosial yang utuh bukan hanya bebas dari penyakit atau kecacatan dalam segala aspek yang berhubungan dengan sistem reproduksi, fungsi dan prosesnya. Kesehatan reproduksi meliputi : alat reproduksi, prilaku seksual remaja, kehamilan, prilaku seksual remaja beresiko, penyakit menular seksual (PMS). Tujuan penelitian ini Mengetahui Gambaran pengetahuan remaja putri tentang kesehatan reproduksi kelas X SMA N 1 Lalan Musi Banyuasin. Metode : Deskriptif kuantitatif dengan desain Cross Sectional dengan tehnik wawancara, alat ukur kuesioner kepada 60 responden dengan tehnik pengambilan sampel secara purposive sampling. Hasil: Pengetahuan tentang alat reproduksi, 34 responden $(56,7 \%)$ mempunyai pengetahuan cukup dan 11 responden $(18,3 \%)$ pengetahuan baik. Pengetahuan tentang prilaku seksual remaja, 25 responden $(41,6)$ mempunyai pengetahuan cukup dan 16 responden $(26,7 \%)$ pengetahuan baik. Pengetahuan tentang kehamilan, 33 responden (55\%) mempunyai pengetahuan cukup dan 5 responden $(8,3 \%)$ pengetahuan baik. Pengetahuan tentang prilaku seksual beresiko, 25 responden (42\%) mempunyai pengetahuan kurang dan 13 responden (21,6\%) mempunyai pengetahuan baik. Pengetahuan tentang penyakit menular seksual (PMS), 35 responden $(58,3 \%)$ mempunyai pengetahuan kurang dan 7 responden $(11,7 \%)$ mempunyai pengetahuan baik. Untuk Meningkatkan pengetahuan remaja harus dilakukan penyuluhan kesehatan ke sekolah, serta diberikan tambahan materi tentang kesehatan reproduksi dan menggunakan fasilitas UKS semaksimal mungkin.

Kata kunci : Pengetahuan; Remaja, Kesehatan Reproduksi
\end{abstract}




\section{PENDAHULUAN}

Abad ke 21 ditandai fenomena transisi kependudukan di Indonesia. Transisi penduduk terbesar adalah proporsi penduduk usia remaja. Terdapat 36.600 .000 (21\% dari total penduduk) remaja di indonesia dan diperkirakan jumlahnya mencapai 43.650.000 pada awal abad ke-21 1. peningkatan proporsi penduduk usia remaja masalah baru terjadi khususnya pada dunia kesehatan yaitu pengetahuan tentang kesehatan remaja. Kesehatan remaja dikembangkan melalui PKPR berupa : peningkatan ketrampilan petugas dan di tambahkan pula materi tentang kesehatan reproduksi remaja yaitu dengan memperkenalkan pelayanan kesehatan peduli remaja (PKPR) dengan pendekatan yang berbeda dimana puskesmas di berikan keleluasaan berinovasi/kreatif untuk meningkatkan akses remaja melalui pendekatan Unit Kesehatan sekolah. Sekolah mempunyai peranan penting dalam pendidikan kesehatan reproduksi ${ }^{2}$.

Kesehatan reproduksi adalah kesejahteraan fisik, mental dan sosial yang utuh bukan hanya tidak adanya penyakit atau kekurangan sesuatu yang berhubungan dengan sistem reproduksi, fungsi - fungsi serta proses-psosesnya $^{3}$. Faktor penyebab mengapa tingkat pengetahuan remaja tentang kesehatan reproduksi masih rendah maka harus ada kerjasama antara pemerintah setempat dengan tenaga kesehatan salah satunya perawat komunitas, peranan penting perawat komunitas yaitu dalam bidang pendidikan kesehatan dan penyuluhan ke masyarakat khususnya pada remaja yang mengalami proses masa transisi, dimana remaja putri mengalami menstruasi serta kurangnya pengetahuan tentang menstruasi baik dari perawatan dan gangguan saat menstruasi yang dapat menyebabkan dampak yang sangat buruk bagi kesehatan reproduksi, kurangnya pengetahuan remaja tentang kesehatan reproduksi akan berdampak pada perilaku seksual ${ }^{4}$. Survey jaringan epidemiologi nasional (JEN) 2006 terhadap 10 universitas di Jakarta, semarang dan Surabaya menyebutkan $15 \%$ dari 2224 mahasiswa pernah melakukan seks pranikah. Adapun akibat kurang pengetahuan itu dampak yang ditimbulkan lainya yaitu akan meningkatnya penularan penyakit menular seksual serta HIV dan AIDS(www.kespro.palembang.com).

SMAN 1 Lalan di kabupaten Musi Banyuasin salah satu sekolah yang berlatar belakang tempat tinggal pedesaan, serta jauh dari perkotaan dan semakin bertambahnya penduduk tidak di seimbangkan dengan pelayanan kesehatan yang memadai (BPS kabupaten Musi Banyuasin, 2009). Data unit kesehatan sekolah SMAN 1 Lalan tiap bulan dilaporkan ada $50 \%$ pertahun megalami gangguan kesehatan reproduksi pada alat reproduksi dan dari data pengunjung guru BP yang konsul dengan keluhan masalah kesehatan reproduksi $40 \%$ pertahun,dari pengunjung tersebut adalah remaja putri yang mengalami nyeri haid yang berlebihan sehingga menyebabkan pingsan. Banyak orang sulit keluar dari masalah akibat pengaruh teman dimasa remaja ${ }^{5}$, dari sifat mereka tersebut sehingga mudah dipengarui dan mudah untuk 
coba-coba terhadap sesuatu baru serta rasa ingin tahunya yang tinggi ${ }^{1}$, maka ini akan memberikan dampak yang sangat buruk bagi remaja yaitu dengan ketidaktahuannya dan mereka melakukan dengan lawan jenisnya pada saat keadaan subur kemudian dapat menyebabkan kehamilan sebelum menikah, kehamilan pada remaja akan berbahaya bagi remaja dan bayinya dapat mengakibatkan keguguran, prematur dan komplikasi perdarahan 5, dampak lain yaitu hilangnya masa depan kerena putusnya pendidikan. Tujuan penelitian ini mengetahui gambaran pengetahuan remaja puti tentang kesehatan reproduksi kelas X SMAN 1 Lalan Musi BanyuAsin.

\section{METODE PENELITIAN}

Jenis penelitian yang digunakan dalam penelitian ini yaitu penelitian deskriptif kuantitatif dengan desain Cross Sectional yang bertujuan untuk melihat gambaran, dimana setiap subjek atau responden hanya di observasi satu kali saja dan sebagai alat ukur ${ }^{6}$. Penelitian ini bertujuan untuk melihat gambaran pengetahuan remaja putri tentang kesehatan reproduksi. Tempat penelitian dilakukan di SMA N 1 LALAN kabupaten Musi Banyuasin, dilaksanakan pada 21 - 23 Juni. maka populasi yang digunakan dalam penelitian ini adalah remaja putri di SMA Negeri 1 Lalan yang berjumlah 203 orang. Sampel merupakan bagian populasi yang akan diteliti atau sebagian jumlah dari karakteristik yang dimiliki oleh populasi 7 . penelitian ini Sebagian dari populasinya yaitu remaja putri kelas $\mathrm{X}$ SMAN 1 Lalan Musi Banyuasin.
Tehnik pengambilan sampel dengan menggunakan purposive sampling yaitu pengambilan sample yang didasarkan pada suatu pertimbangan tertentu yang dibuat oleh peneliti sendiri berdasarkan pertimbangan orang-orang yang berpengalaman, sampel berjumlah 60 orang. Kriteria pengambilan sampel dengan menggunakan kriteria inklusi sebagai berikut :

1. Remaja putri yang duduk di bangku kelasX di SMAN 1 Lalan

2. Siswa yang bersedia dijadikan responden

3. Dapat diajak berkomunikasi

4. Tidak sedang sakit

Data primer yang digunakan dalam penelitian ini adalah informasi yang didapat melalui hasil pengisian kuesioner. Data sekunder yang digunakan adalah informasi yang di dapat melalui pengamatan langsung terhadap dokumen tertulis seperti laporan tahunan Puskesmas, laporan unit kesehatan sekolah, laporan Kemahasiswaan, dan guru BP serta data - data lain yang mendukung Analisa data dilakukan terhadap data yang telah dikumpulkan menggunakan analisa Univariat, untuk mengetahui distribusi frekuensi tiap variabel penelitian. penelitian ini mengggunakan kuisioner pengetahuan berjumlah 50 pertanyaan yang terbagi menjadi 5 item yaitu alat reproduksi, prilaku seksual remaja, kehamilan, perilaku seksual remaja beresiko, penyakit menular seksual (PMS).

Pertanyaan dari kuisioner berupa pertanyaan dengan pilihan berganda dibuat kunci jawaban terlebih dahulu. Jawaban reponden akan dianggap benar apabila sesuai dengan kunci jawaban dan di beri skor 1, sedangkan untuk jawaban yang salah diberi skor 0. 
untuk mengiterprestasikan data yang digunakan kriteria standar objektif sebagai berikut:

1. Kurang, jika jawaban benar memperoleh skor $<50 \%$

2. Cukup, jika jawaban benar memperoleh skor $\geq 50-70 \%$
3. Baik, jika jawaban benar memperoleh skor $\geq 70 \%$ (Nursalam, 2003)

Hasil penelitian yang sudah di tabulasikan maka akan dilakukan Analisa data mengunakan data univariat.

\section{HASIL DAN PEMBAHASAN}

A. Alat reproduksi.

\begin{tabular}{ccc}
\hline Pengetahuan Alat Reproduksi & Frekuensi & Persentase \\
\hline Kurang & 15 & 25 \\
Cukup & 34 & 56,7 \\
Baik & 11 & 18,3 \\
Total & 60 & 100 \\
\hline
\end{tabular}

Hasil penelitian menunjukkan pengetahuan remaja putri kelas $\mathrm{X}$ SMAN 1 Lalan Musi Banyuasin tentang alat reproduksi, 34 orang $(56,6$ $\%)$ mempunyai pengetahuan cukup dan 11 orang $(18,3 \%)$ mempunyai pengetahuan baik. Maka asumsi peneliti bahwa remaja putri mempunyai pengetahuan cukup tentang alat reproduksi sesuai dengan hasil penelitian dan pembanding hasil penelitian terdahulu kemungkinan disebabkan dari mata ajar biologi kelas $\mathrm{X}$ (sepuluh) dimana pernah diajarakan waktu SMP jadi rata - rata pengetahuannya cukup dikarenakan sudah di pelajari, akan tetapi itu tidak bertahan lama karena tidak di ajarkan lagi, selain itu jauhnya tempat sekolah dengan perkotaan tepatnya didesa sehingga membuat siswa susah untuk mengakses sumber informasi dari luar sekolah dan tidak adanya tempat untuk siswa mempelajari bahasan tentang pelajaran reproduksi, serta siswa tidak mendapatkan materi tentang alat reproduksi. Kurangnya fasilitas pendukung bagi siswa, serta keterbatasan sumber daya manusia yang memberikan materi tentang alat reproduksi serta belum dilakukan penyuluhan oleh sekolah atau instansi kesehatan.

\section{B. Perilaku seksual remaja}

\begin{tabular}{clc}
\hline $\begin{array}{c}\text { Pengetahuan Perilaku Seksual } \\
\text { Remaja }\end{array}$ & Frekuensi & Persentase \\
\hline Kurang & 19 & 31,7 \\
Cukup & 25 & 41,6 \\
Baik & 16 & 26,7 \\
Total & 60 & 100 \\
\hline Hasil penelitian menunjukkan & SMA N 1 Lalan Musi Banyuasin \\
pengetahuan remaja putri kelas X & tentang perilaku seksual remaja, 25
\end{tabular}


orang (41,6 \%) mempunyai pengetahuan cukup dan 16 orang $(26,7$ $\%)$ mempunyai pengetahuan baik. Maka asumsi peneliti bahwa pengetahuan remaja putri digolongkan cukup tentang prilaku seksual remaja sesuai dengan hasil penelitian dan pembanding hasil penelitian terdahulu, ini kemungkinan disebabkan oleh tidak adanya wadah untuk mencari informasi yang tepat untuk mendapatkan pengetahuan tentang prilaku seksual remaja dan kurang aktifnya Unit Kesehatan Sekolah, dimana siswa dapat mengembangkan bakatnya serta mencari informasi tentang kesehatan, serta tidak adanya tempat praktik ataupun ekstra kulikuler yang berperan dalam bidang kesehatan reproduksi. Sehingga siswa hanya mengetahuai sebatas yang mereka dapat dari pelajaran sekolah dan lingkungan yang mereka tempati sedangkan di sekolah belum pernah diberikan penyuluhan tentang materi prilaku seksual remaja, serta susahnya mencari informasi karena jauhnnya jarak dari kota sehingga siswa hanya mendapatkan dari sekolah dan keluarga.

\section{Kehamilan}

\begin{tabular}{ccc} 
Pengetahuan kehamilan & Frekuensi & Persentase \\
Kurang & 22 & 36,7 \\
Cukup & 33 & 55 \\
Baik & 5 & 8,3 \\
Total & 60 & 100 \\
\hline
\end{tabular}

Hasil penelitian menunjukkan remaja putri kelas X SMA N 1 Lalan Musi Banyuasin tentang kehamilan, 33 orang (55\%) mempunyai pengetahuan cukup dan 5 orang $(8,3 \%)$ mempunyai pengetahuan baik. Maka asumsi peneliti bahwa pengetahuan remaja putri cukup tentang kehamilan sesuai dengan hasil penelitian dan pembanding hasil penelitian terdahulu, ini kemungkinan disebabkan siswa sudah pernah mendapatkan mata ajar tentang reproduksi pada waktu SMP sehingga siswa masih ingat tentang materi kehamilan, akan tetapi itu tidak bertahan lama di buktikan dengan hasil penelitian hanya $8,3 \%$ siswa yang pengetahuan tentang kehamilan yang baik, selain itu tidak adanya program dari sekolah tentang penyuluhan kesehatan, kurangnya informasi dari sekolah tentang kehamilan, tentang resiko yang ditimbulkan jika terjadi kehamilan pada usia remaja, selain itu putusnya sekolah sehingga masa depan suram dan mendapat gunjingan dari masyrakat. 
D. Perilaku seksual remaja beresiko

\begin{tabular}{ccc}
\hline $\begin{array}{c}\text { Pengetahuan Perilaku Seksual } \\
\text { Remaja Beresiko }\end{array}$ & Frekuensi & Persentase \\
\hline Kurang & 25 & 41,7 \\
Cukup & 22 & 36,7 \\
Baik & 13 & 21,6 \\
Total & 60 & 100 \\
\hline
\end{tabular}

Hasil penelitian menunjukkan pengetahuan remaja putri kelas $X$ SMA N 1 Lalan Musi Banyuasin tentang prilaku seksual remaja beresiko, 25 orang $(41,7 \%)$ mempunyai pengetahuan kurang dan 13 orang $(21,6 \%)$ mempunyai pengetahuan baik. Maka asumsi peneliti pengetahuan remaja putri kurang tentang prilaku seksual remaja beresiko sesuai dengan hasil penelitian dan pembanding hasil penelitian terdahulu, kemungkinan disebabkan oleh tidak adanya fasilitas informasi yang dapat di akses oleh siswa untuk memperoleh pengetahuan diluar mata ajar yang di berikan,kurangnya sumber daya manusia yang memberikan materi tentang prilaku seksual remaja, serta belum pernah

E. Penyakit menular seksual remaja (PMS)

\begin{tabular}{ccc}
\hline $\begin{array}{c}\text { Pengetahuan Penyakit Menular } \\
\text { Seksual (PMS) }\end{array}$ & Frekuensi & Persentase \\
\hline Kurang & 35 & 58,3 \\
Cukup & 18 & 30 \\
Baik & 7 & 11,7 \\
Total & 60 & 100 \\
\end{tabular}

Hasil penelitian menunjukkan pengetahuan remaja putri kelas $\mathrm{X}$ SMA N 1 Lalan Musi Banyuasin dilakukan penyuluhan pada siswa tentang kesehatan, tidak berjalannya Unit Kesehatan Sekolah. Penyebab lainnya yaitu belum didapatkan pelajaran biologi tentang kesehatan reproduksi, pada pelajaran biologi haya mempelajari tentang anatomi reproduksi dan proses pembuahan sehingga siswa kurang mengerti dan memahami, maka prilaku seksual remaja beriko tidak termasuk materi yang diajarkan sehingga siswa hanya mendapatkan dari luar sekolah, yang di buktikan dengan hasil penelitian yaitu yang mempunyai pengetahuan baik hanya 21,6 \% dari 60 siswa. Sehingga pengetahuan dari luar yang tidak dapat di pertanggungjawabkan yang tidak tahu sumber kebenarannya. 
$21,7 \%$ ) mempunyai pengetahuan baik. Maka asumsi peneliti bahwa pengetahuan remaja putri kurang tentang penyakit menular seksual (PMS) sesuai dengan hasil penelitian dan pembanding hasil penelitian terdahulu, ini disebabkan oleh tidak adanya penyuluhan dari pendidikan serta tidak adanya materi yang menjelaskan tentang PMS, ini sangat mengkwatirkan dengan banyaknya remaja yang tidak mengetahui pentingnya PMS, selain itu kuranya informasi yang jelas tentang PMS dan tidak adanya sumber informasi yang memadai di karenakan tempat yang jauh dari perkotaan, tidak adanya kegiatan ekstra kulikuler yang aktif dalm bidang kesehatan, serta tidak berjalannya UKS sehingga tidak ada wadah siswa untuk belajar tentang kesehatan, belum adanya fasilitas yang mendukung siswa untuk belajar tentang kesehatan.

\section{SIMPULAN}

Pengetahuan siswi SMAN 1
Lalan Musi Banyuasin dari hasil
penelitian di dapatkan bahwa untuk
pengetahuan alat reproduksi cukup,
perilaku seksual cukup, kehamilan
kurang, Perilaku seksual remaja
beresiko kurang, penyakit menular
seksual kurang, dari rata-rata tersebut
maka dapat disimpulkan bahwa
pengetahauan tentang kesehtan
reproduksi masih kurang.

\section{SARAN}

Hendaknya profesi keperawatan dapat ikut berpartisipasi dalam memberikan penyuluhan dan promosi kesehatan kepada masyarakat dan khususnya pada remaja sesuai dengan peran pada bidangnya masing-masing.
Bagi masyarakat hendaknya selalu terbuka tehadap hal - hal yang baru yang bersifat positip serta memeberikan pendidikan sejak dini tentang kesehatan reproduksi agar tidak terjerumus ke hal-hal yang akan berdampak pada masa depannya. Dengan sikap terbuka terhadap anak, anak akan lebih memahami dan mengerti apa yang seharusnya dilakukan dan tidak bagi dirinya serta meningkatkan pengetahuan remaja harus dilakukan penyuluhan kesehatan ke sekolah, serta di berikan tambahan materi tentang kesehatan reproduksi dan menggunakan fasilitas UKS semaksimal mungkin, menyertakan masyarakat ikut ambil bagian dalam pendidikan di rumah karena keluarga sangat berperan penting pada tahap perkembangan remaja.

\section{DAFTAR PUSTAKA}

1. Notoatmodjo, Soekidjo.2007.Promosi

Kesehatan Dan Ilmu

Prilaku.Jakata; Rineka Cipta.

2. Badan Pusat Statistik

Jakarta,Indonesia.Survey

Kesehatan Reproduksi Remaja

Indonesia 2007.Jakarta:

Depatemen Kesehatan dan

BPS Jakarta

3. DEPKES RI.1999.kesehatan reproduksi remaja( KRR) :buku saku remaja untuk usia 41-19 tahun.Jakarta: DEPKES RI

4. Anies.2005.Pencegahan Dini Gangguan Kesehatan.Jakarta : PT Elek Media Komputindo

5. DEPKES RI.2005.Kebijakan Dan Strategi Nasional Kesehatan Reproduksi Di Indonesia.Jakarta: DEPKES RI 
6. Budiarto,

Eko.2002.biostatistika.Jakarta:

EGC

7. Nursalam.2008.Konsep Dan

Penerapan Medologi
Penelitian ilmu

Keperawatan.Jakarata:

Salemba Medika 